\title{
Is Mental Toughness in Elite Athletes a Predictor of Moral Disengagement in Sports?
}

\author{
Sevinc Namli ${ }^{1} \&$ Gonul Tekkursun Demir ${ }^{2}$ \\ ${ }^{1}$ Department of Physical Training and Sports, Erzurum Technical University, Erzurum, Turkey \\ ${ }^{2}$ Department of Physical Training and Sports, Gazi University Faculty of Sports, Ankara, Turkey \\ Correspondence: Sevinc Namli, Department of Physical Training and Sports, Erzurum Technical University, \\ 25100-Yakutiye/Erzurum, Turkey. E-mail: sevinc.namli@erzurum.edu.tr
}

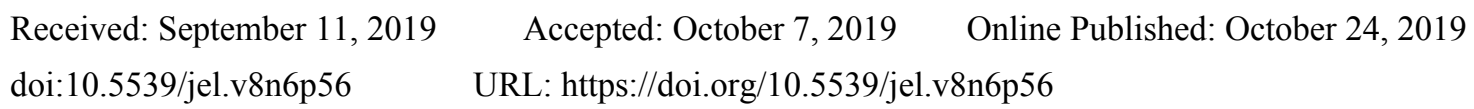

\begin{abstract}
The aim of this study was to determine whether mental toughness levels of athletes engaged in the elite-level team and individual sports in Ankara and Erzurum were predictors of moral disengagement in sports. The sample of the study consisted of randomly-selected 515 athletes who were actively engaged in sports in their clubs in 2017. The "Moral Disengagement in Sport Scale-Short" (MDSS) developed by Boardley and Kavussanu (2008) and adapted to Turkish by Gülpınar (2015), and the "Sports Mental Toughness Questionnaire" (SMTQ) developed by Sheard et al. (2009) and adapted to Turkish by Pehlivan (2014) were used as data collection tools. In the analysis of the data, frequency, percentage, Pearson Product-Moment Correlation Coefficient and linear regression analysis were utilized.

As a result of the analyzes, no significant difference was found between confidence, one of the sub-scales of the SMTQ, and moral disengagement, but there was a weak positive significant relationship between the constancy and control sub-scales. As a result of the linear regression analysis, it was found that moral disengagement predicted the constancy and control sub-scales significantly and explained $4 \%$ and $3 \%$ of the variance, respectively, but it was found that the confidence sub-scale was not predicted significantly.
\end{abstract}

Keywords: sports, athlete, mental toughness, moral disengagement

\section{Introduction}

Performance in all sports branches is affected by psychological status, motivation, concentration and mental factors as well as many physical characteristics such as toughness, strength, speed, agility etc. It can be stated that athletes' skills that require mental toughness, such as correct decision making under stress-difficult conditions, staying calm under pressure and overcoming problems are intertwined with their performance. In this context, mental toughness is one of the critical skills for reaching ultimate success.

Mental toughness is the one's maintaining the competition with himself/herself and others, having unshakable confidence and coping successfully with oppression and difficulties by dealing with troubles thanks to the desire to succeed (Clough et al., 2002). According to Gucciardi, Gordon and Dimmock (2008), mental toughness includes orientation to competition, focus and concentration, quality preparation, goal setting, positive attitude, self-confidence, decision-making, motivation, perseverance and commitment, and overcoming the pressure. According to Jones, Hanton and Connaughton (2002), mental toughness is to enjoy the pressure, to recover oneself even after difficult situations, to maintain self-confidence, to show an effective performance against unfavorable settings under a competitive and stressful condition. In the literature, mental toughness is conceptualized as being psychologically durable and well (Connaughton, Wadey, Hanton, \& Jones, 2008; Crust, 2008; Gucciardi, Hanton, \& Mallett, 2012; Tekkurşun Demir et al., 2018; Tekkurşun Demir \& Türkeli, 2018), the process of success and adaptation (Hunter, 2001), ability to overcome failure or to resist failure (Goldberg, 1998; Taylor, 1989; Woods, Hocton, \& Desmond, 1995).

Sports, by its nature, is a social setting that requires communication and interaction among its participants. Such a social structure may pose undesired behaviors such as lying, provoking others and causing others to be injured while it may help generate positive behaviors such as helping the injured opponent and encouraging and supporting a poorly performing teammate (Kavussanu, 2008; AF). The first scenario is defined as moral 
disengagement in sports. According to Bandura (1999), moral disengagement is the creation of a belief that criminal behaviors are acceptable to achieve a goal by representing them as if they were important. Moral disengagement in sports is defined as demonstrating negative social behaviors such as injuring and cheating on a player deliberately and retaliation with a serious foul against others (Kavussanu, Seal, \& Phillips, 2006), breaking the rules and not accepting it, and saying bad words (Boardley \& Kavussanu, 2011), lying to hide the offensive activities (Bandura, 1999), blaming the coach for unsporting behaviors (Boardley \& Kavussanu, 2011), continuing to harm others and ignoring the bad results (Bandura, 1999).

Considering the fact that the researchers take each psychological characteristic into account as mental toughness (Crust, 2007), the effect of mental toughness on moral disengagement syndrome in sports is one of the questions that come to mind. In the literature, it has not been found any studies conducted on the effect of mental toughness level on moral disengagement in sports. Therefore, examining the effect of mental toughness level on "moral disengagement", which causes aggressive and criminal behavior in sports, reveals the importance of the current study.

\section{Method}

In this section, design and participants of the study, and data collection tools and data analyses are addressed.

\subsection{Design of the Study}

This is a correlational study in descriptive survey design. Survey design is a suitable design for studies aiming to describe a situation that existed in the past or exists in the present as it is (Karasar, 2006). Such a design is used for studies that aim to determine the presence or degree of co-change between two and more variables (Cohen, Manion, \& Morrison, 2000; Karasar, 2006).

\subsection{Sample}

The sample of the study consisted of 515 athletes who were engaged in elite-level team and individual sports in Ankara and Erzurum in 2017. In the study, criterion sampling, which provides an in-depth research opportunity (Patton, 2014), was used. In criterion sampling, the researcher may establish a predetermined criterion or criteria (Yıldırım \& Şimşek, 2011). The criteria for the athletes participating in the study are to be active in the activities of the federations of the branch they are engaged in, to be registered within a federation for at least two years and to be actively engaged in sports. The researcher paid attention to the number of participants in both individual and team sports to be close to each other (Athletics 28, Badminton 24, Basketball 48, Bocce 29, Boxing 18, Ice Hockey 31, Curling 18, Field Hockey 33, Dart 15, Soccer 44, Wrestling 16, Handball 41, Karate 16, Skiing 18, Sledding 20, Rowing 17, Taekwondo 19, Tennis 17, Volleyball 43 and Swimming 20).

Table 1. Gender, branches and age of the participants

\begin{tabular}{lllll}
\hline Branches & Grander & & $\mathrm{N}$ & Percent \\
\hline İndividual & Female & & 105 & 20.40 \\
& Male & & 170 & 33.00 \\
Team & Female & & 79 & 15.30 \\
& Male & & 161 & 31.30 \\
Total & & 515 & 100 \\
Age & Mean & Age & $\mathrm{N}$ & Percent \\
& 20.59 & 16 & 49 & 9.5 \\
& & 17 & 64 & 12.4 \\
& & 18 & 65 & 12.6 \\
& & 19 & 48 & 9.3 \\
& & 20 & 49 & 9.5 \\
& & 21 & 44 & 8.5 \\
& & 22 & 49 & 9.5 \\
& & 23 & 30 & 5.8 \\
& & 24 & 28 & 6.8 \\
& & 25 & 22 & 5.4 \\
& & 26 & 32 & 4.3 \\
& & 27 & 515 & 6.2 \\
& & & 100.0 \\
\hline
\end{tabular}


Table 1 shows gender, sports branches and age of the participants. Accordingly, while $20 \%$ of individual branches are composed of female athletes $(n=105)$ and $33 \%$ are composed of male athletes $(n=170), 16 \%$ of team branches are composed of female athletes $(n=79)$ and $31 \%$ are composed of male athletes $(n=161)$. The age range of the participants is 16-27. Most of the participants were 18 years with $12.6 \%$ and 17 years with $12.4 \%$. The lowest participant rate was $4.3 \%$ and 26 years old athletes.

\subsection{Data Collection Tools}

The Moral Disengagement in Sport Scale-Short (MDSS): This one-dimensional 8-item scale, which was developed by Boardley and Kavussanu (2008) and adapted to the Turkish culture by Gülpınar (2015), was used in the study. Cronbach Alpha coefficient was found to be 0.78 in the original version of the scale. It was observed that fit indices obtained as a result of the confirmatory factor analysis were good or excellent in all parameters. All the items for measuring attitudes of moral disengagement in sports have negative meanings. Higher scores on the scale mean greater moral disengagement in sports.

The Sports Mental Toughness Questionnaire (SMTQ): This three-dimensional 13-item scale, which was developed by Sheard et al. (2009) and adapted to the Turkish culture by Pehlivan (2014), was used in the study. The sub-scales are "confidence", "constancy" and "control". The Cronbach Alpha coefficient of the scale was measured as 0.72 . The first sub-scale of the scale (Confidence) consists of 5 items and the other two sub-scales (Constancy and Control) consist of 4 items. The responses (from "strongly agree" to "strongly disagree") in this four-point Likert type scale are marked as A, B, C and D, respectively. The items between 1-7 are positive statements and the ones between $8-13$ are negative statements. The total score was taken into account for the whole scale or its sub-scales. It was found that fit indices for the scale as a result of CFA were at good level $\left(\chi^{2}\right.$ $=147.02 ; \mathrm{sd}=61 ; \chi 2 / \mathrm{sd}=2.41 ; \mathrm{RMSEA}=0.06 ; \mathrm{SRMR}=0.06 ; \mathrm{GFI}=0.94 ; \mathrm{CFI}=0.91 ; \mathrm{NFI}=0.86 ; \mathrm{NNFI}=$ 0.88 ; RMR $=0.04$ ), and that $\mathrm{t}$ values for all items were significant at the 0.01 level and the data fitted the model well.

\subsection{Data Analysis and Interpretation}

This section includes predictors of leadership characteristics of sports high school students, analyses of relationships between these predictors, and the results for the confirmatory factor analysis performed to test the conformity of the scales administered to the sample. SPSS 23.0 package program was used for statistical analyses of the data. Confirmatory factor analysis was performed on both scales to determine the conformity of the scales administered to the sample and their construct validities were tested. In the context of this analysis, obtained values were examined through Chi-square/Degree of freedom $\left(\chi^{2} / \mathrm{df}\right)$, Root Mean Square Error of Approximation (RMSEA), Root Mean Square Residual (RMR), Standardized Root Mean Square Residual (SRMR), Goodness of Fit Index (GFI), Adjusted Goodness of Fit Index (AGFI), Normed Fit Index (NFI), Non-Normed Fit Index (NNFI), Comparative Fit Index (CFI) and Incremental Fit Index (IFI). LISREL 8.8 program was utilized for confirmatory factor analysis. According to the results of the confirmatory factor analysis, RMSEA values of the models reached on two scales were found to be .06 for the MDSS, and .07 for the SMTQ. Within the framework of these proposed values, RMSEA values obtained on both scales were determined to be acceptable without any modification. In addition, it was understood that other goodness of fit indices were acceptable within the criterion values mentioned in the literature (Sümer, 2000; Schermelleh-Engel \& Moosbrugger, 2003; Tabachnick \& Fidell, 2007; Kline, 2015) and these values were used as evidence for the conformity of the scales. Upon the data obtained from the sample, Cronbach Alpha $(\alpha)$ coefficients were calculated as .73 for the MDSS, .71 for the confidence sub-scale, .68 for the constancy sub-scale, .73 for the control sub-scale, and .78 for the total score of the scale. In the study, a normality test and detection of outliers were done first for the suitability of analyses and for the hypothesis testing. As a result, erroneous and missing data and outliers from a total of 25 participants were excluded and the analyses were conducted on the data of 515 athletes. Skewness-Kurtosis values of each independent variable were found to be distributed between \pm 1 . George and Malley (2014) stated that scores do not show a significant deviation from the normal distribution and it is appropriate to carry out normality tests if the skewness coefficient is within \pm 2 limits. Therefore, standard (Enter) regression analysis was used to examine the predictive levels. T-test was used to determine the difference between independent samples; Pearson correlation analysis was performed to determine the relationships between variables; and linear regression analysis was conducted to determine the strengths of each sub-scales of mental toughness in predicting the total score of moral disengagement.

\section{Findings}

Regression equations (1) and (2) were established to determine the interaction between the MDSS (MD) and SMTQ (MT) and demographic characteristics. 


$$
\begin{aligned}
& \mathrm{MT}=\mathrm{C}+\mathrm{E}+\mathrm{B}+\mathrm{A}+\mathrm{G}+\mathrm{e} \\
& \mathrm{MD}=\mathrm{C}+\mathrm{E}+\mathrm{B}+\mathrm{A}+\mathrm{G}+\mathrm{e}
\end{aligned}
$$

Table 2. Regression analysis results for the SMTQ (MT) and demographic characteristics

\begin{tabular}{llllc}
\hline Variable & Coefficient & Standard Error & t statistics & Probability \\
\hline C & 2.894 & 0.141 & 20.40 & 0.000 \\
Experience (E) & 0.002 & 0.005 & 0.478 & 0.632 \\
Branch (B) & -0.002 & 0.003 & -0.764 & 0.444 \\
Age $(\boldsymbol{A})$ & $\mathbf{0 . 0 1 1}$ & $\mathbf{0 . 0 0 6}$ & $\mathbf{1 . 7 5 1}$ & $\mathbf{0 . 0 8 0}$ \\
Gender (G) & -0.046 & 0.046 & -1.006 & 0.314 \\
$\mathrm{R}^{2}$ & \multicolumn{2}{c}{ Probability } & $\mathbf{0 . 0 0 7}$ \\
F statistics & \multicolumn{2}{c}{ Durbin-Watson } & 1.580 \\
\hline
\end{tabular}

In Table 2, revealing the results for the first regression model, it was found that the model is statistically significant at $1 \%$ significance level. Accordingly, the variable mental toughness is significantly and positively affected by the variable age at $1 \%$ significance level. In other words, it can be stated that the older the athletes get, the stronger the mental toughness they have. The variables experience, branch and gender have no effect on the variable mental toughness at $10 \%$ level.

Table 3. Regression analysis results for the MDSS (MD) and demographic characteristics

\begin{tabular}{llllc}
\hline Variable & Coefficient & Standard Error & t statistics & Probability \\
\hline C & 4.681 & 0.337 & 13.883 & 0.000 \\
Experience (E) & 0.003 & 0.014 & 0.267 & 0.789 \\
Branch (B) & 0.004 & 0.008 & 0.459 & 0.646 \\
Age $(\boldsymbol{A})$ & $\mathbf{- 0 . 0 5 4}$ & $\mathbf{0 . 0 1 5}$ & $\mathbf{- 3 . 4 9 4}$ & $\mathbf{0 . 0 0 0}$ \\
Gender $(\boldsymbol{G})$ & $\mathbf{- 0 . 3 0 8}$ & $\mathbf{0 . 1 1 0}$ & $\mathbf{- 2 . 7 9 5}$ & $\mathbf{0 . 0 0 5}$ \\
$\mathrm{R}^{2}$ & \multicolumn{2}{c}{0.04} & Probability & $\mathbf{0 . 0 0 0}$ \\
F statistics & \multicolumn{2}{c}{ Durbin-Watson } & 1.722 \\
\hline
\end{tabular}

Results for the second regression model are given in Table 3. It was determined that the second model is statistically significant at $1 \%$ significance level, and that the MDSS is affected significantly and negatively by the variable age at $1 \%$ significance level and by the variable gender at $5 \%$ significance level. Considering the fact that the higher scores the athletes get from the MDSS, the more disengaged they are, it can be stated that athletes get more engaged in morality as they get older. In addition, females are more engaged in morality than males. However, it was determined that there is no relationship between the variables experience and branch and the variable disengagement in sports.

The Pearson Correlation Analysis was conducted to examine the relationship between the SMTQ and MDSS. The correlation between the variables is presented in Table 4 .

Table 4. Correlation analysis results for the SMTQ and MDSS

\begin{tabular}{llll}
\hline Variables & & Mental & Morality \\
\hline Mental Toughness & Pearson Correlation & 1 & $-0.188^{* *}$ \\
& Significance & & .000 \\
& $\mathrm{~N}$ & 515 & 515 \\
Moral Disengagement in Sports & Pearson Correlation & $-0.188^{* *}$ & 1 \\
& Significance & .000 & \\
& $\mathrm{~N}$ & 515 & 515 \\
\hline
\end{tabular}

The results for the correlation between the SMTQ and MDSS are given in Table 4. Accordingly, a significant and negative relationship is found between the variables at $1 \%$ significance, which means that a participant who is morally engaged in sports has a stronger mental toughness. Concordantly, higher scores in the SMTQ means that athletes may demonstrate more moral behaviors.

Regression equations (3) and (4) were established to determine the degree of interaction between the MDSS 
(MD) and SMTQ (MT).

$$
\begin{aligned}
& \mathrm{MT}=\mathrm{C}+\mathrm{MD}+\mathrm{e} \\
& \mathrm{MD}=\mathrm{C}+\mathrm{MT}+\mathrm{e}
\end{aligned}
$$

Table 5 presents the prediction results for the regression model established to determine the effect of the MDSS on the SMTQ.

\begin{tabular}{|c|c|c|c|c|}
\hline \multicolumn{5}{|c|}{ Dependent Variable: Mental toughness (MT) } \\
\hline Variable & Coefficient & Standard Error & t statistics & Probability \\
\hline $\mathrm{C}$ & 3.318 & 0.061 & 54.130 & 0.000 \\
\hline Moral disengagement in sports (MD) & -0.089 & 0.020 & -4.336 & 0.000 \\
\hline $\mathrm{R}^{2}$ & \multirow{2}{*}{0.035} & \multicolumn{2}{|c|}{ Probability } & 0.000 \\
\hline F statistics & & \multicolumn{2}{|c|}{ Durbin-Watson } & 1.654 \\
\hline
\end{tabular}

Table 5. Regression analysis results for the SMTQ

In Table 5, it was found that the third model is statistically significant at $1 \%$ significance level, and that the variable moral disengagement in sports affects the variable mental toughness negatively and significantly at $1 \%$ significance level. In other words, the lower scores the participants get from the MDSS, the stronger mental toughness they have. It was also found that a decrease in moral values by 1 unit may cause an increase of 0.089 in mental toughness.

Table 6 presents the prediction results for the regression model established to determine the effect of the SMTQ on the MDSS.

Table 6. Regression analysis results for the MDSS

\begin{tabular}{lllll}
\hline \multicolumn{5}{l}{ Dependent Variable: Moral disengagement in sports (MD) } \\
\hline Variable & Coefficient & Standard Error & t statistics & Probability \\
\hline C & 4.015 & 0.284 & 14.125 & 0.000 \\
Mental toughness $(\mathbf{M T})$ & $\mathbf{- 0 . 3 9 6}$ & $\mathbf{0 . 0 9 1}$ & -4.336 & $\mathbf{0 . 0 0 0}$ \\
$\mathrm{R}^{2}$ & 0.035 & \multicolumn{2}{c}{ Probability } & $\mathbf{0 . 0 0 0}$ \\
F statistics & 18.800 & \multicolumn{2}{c}{ Durbin-Watson } & 1.654 \\
\hline
\end{tabular}

In Table 6, revealing the results of regression analysis conducted to determine the effect of mental toughness levels of the athletes on their moral disengagement in sports levels, it was found that the fourth model is statistically significant at $1 \%$ significance level. The variable mental toughness affects the variable moral disengagement in sports significantly and negatively at $1 \%$ significance level. In other words, it can be asserted that an increase in the scores in the SMTQ by 1 unit may cause a decrease of 0.396 in the MDSS, which means that such an increase will lead the athletes to be more engaged in moral values.

Considering the results for the 3rd and 4th regression models, it was discovered that the effect of the variable mental toughness on the variable moral disengagement (0.396) is greater than vice versa $(0.089)$. Consequently, it can be stated that improving the activities aiming at increasing the mental development of athletes will contribute to their mental toughness as well as to their moral engagement in sports.

Regression models numbered 5, 6 and 7 were established to determine the effects of three sub-scales of the SMTQ on the variable moral disengagement in sports.

$$
\begin{aligned}
& \mathrm{CN}=\mathrm{C}+\mathrm{MD}+\mathrm{e} \\
& \mathrm{CO}=\mathrm{C}+\mathrm{MD}+\mathrm{e} \\
& \mathrm{CT}=\mathrm{C}+\mathrm{MD}+\mathrm{e}
\end{aligned}
$$

In the models;

$\mathrm{CN}=$ Constancy,

$\mathrm{CO}=$ Confidence

$\mathrm{CT}=\mathrm{Control}$ and

$\mathrm{MD}=$ Moral disengagement. 
The results for the regression equation numbered 5, which was established to determine the effect of the constancy sub-scale on the MDSS, are presented in Table 7.

Table 7. Regression analysis results for the constancy sub-scale and moral disengagement in sports

\begin{tabular}{lllll}
\hline Dependent Variable: & Moral disengagement (MD) & & \\
\hline Variable & Coefficient & Standard Error & t statistics & Probability \\
\hline C & 3.966 & 0.283 & 14.007 & 0.000 \\
Constancy $(C N)$ & $-\mathbf{0 . 3 4 3}$ & $\mathbf{0 . 0 8 2}$ & -4.178 & $\mathbf{0 . 0 0 0}$ \\
$\mathrm{R}^{2}$ & 0.033 & \multicolumn{2}{c}{ Probability } & $\mathbf{0 . 0 0 0}$ \\
F statistics & 17.462 & \multicolumn{2}{c}{ Durbin-Watson } & 1.678 \\
\hline
\end{tabular}

In Table 7 , it was determined that the fifth model is statistically significant at $1 \%$ significance level, and that the constancy sub-scale has a negative effect on the MDSS at $1 \%$ significance level. An increase in the scores in the constancy sub-scale by 1 unit will cause a decrease of 0.343 in the MDSS, which means the greater constancy the athletes demonstrate, the further moral values they are engaged in.

The results for the regression equation numbered 6, which was established to determine the effect of the confidence sub-scale on the MDSS, are presented in Table 8.

Table 8. Regression analysis results for the confidence sub-scale and moral disengagement in sports

\begin{tabular}{lllll}
\hline \multicolumn{2}{l}{ Dependent Variable: } & Moral disengagement (MD) & & \\
\hline Variable & Coefficient & Standard Error & t statistics & Probability \\
\hline $\mathrm{C}$ & 3.073 & 0.229 & 13.410 & 0.000 \\
Confidence (CO) & $\mathbf{- 0 . 0 8 9}$ & $\mathbf{0 . 0 7 2}$ & $\mathbf{- 1 . 2 2 6}$ & $\mathbf{0 . 2 2 0}$ \\
$\mathrm{R}^{2}$ & 0.002 & \multicolumn{2}{c}{ Probability } & 0.220 \\
F statistics & 1.504 & \multicolumn{2}{c}{ Durbin-Watson } & 1.644 \\
\hline
\end{tabular}

In Table 8 , it was found that the sixth regression model is statistically insignificant at $10 \%$, which means there is no statistically significant relationship between the confidence sub-scale and the MDSS.

The results for the regression equation numbered 7 , which was established to determine the effect of the control sub-scale on the MDSS, are presented in Table 9.

Table 9. Regression analysis results for the control sub-scale and moral disengagement in sports

\begin{tabular}{lllll}
\hline Dependent Variable: Moral disengagement (MD) & & & \\
\hline Variable & Coefficient & Standard Error & t statistics & Probability \\
\hline C & 3.539 & 0.171 & 20.672 & 0.000 \\
Control $(C T)$ & $\mathbf{- 0 . 2 7 2}$ & $\mathbf{0 . 0 6 0}$ & -4.485 & $\mathbf{0 . 0 0 0}$ \\
$\mathrm{R}^{2}$ & 0.037 & \multicolumn{2}{c}{ Probability } & 0.000 \\
F statistics & 20.129 & \multicolumn{2}{c}{ Durbin-Watson } & 1.686 \\
\hline
\end{tabular}

In Table 9, it was determined that the seventh model was statistically significant at $\% 1$ significance level, and that the control sub-scale had a negative effect on the MDSS at $1 \%$ significance level. In other words, an increase in the scores in the control sub-scale by 1 unit will cause a decrease of 0.272 in the MDSS, which means the greater control the athletes gain, the further the moral values they are engaged in.

Given the results for the SMTQ and MDSS, it may be suggested that providing training opportunities to athletes to enable them to improve themselves in terms of the themes covered by both scales will have positive contributions on both variables. Moreover, it can be stated that further intensification of training based on the themes covered by the constancy and control sub-scales will contribute significantly to their engagement in moral values as well as improve their mental capabilities.

\section{Discussion and Conclusion}

The aim of this study was to determine whether mental toughness levels of athletes engaged in the elite-level team and individual sports were predictors of moral disengagement in sports. 
In the study, it was found that the first regression model is statistically significant at $1 \%$ significance level. Accordingly, the variable mental toughness is significantly and positively affected by the variable age at $1 \%$ significance level. In other words, it can be stated that the older the athletes get, the stronger the mental toughness they have. In parallel with our results, Yarayan et al. (2018), Crust et al. (2014), Marchant et al. (2009) and Nicholls et al. (2009) also reported that mental toughness develops as the one gets older. It was found that the variables experience, branch and gender have no effect on the variable mental toughness at $10 \%$ level.

In another finding of the study, it was concluded that the second model is statistically significant at $1 \%$ significance level, and that the MDSS is affected significantly and negatively by the variable age at $1 \%$ significance level and by the variable gender at $5 \%$ significance level. Considering the fact that the higher scores the athletes get from the MDSS, the more disengaged they are, it can be stated that athletes get more engaged in morality as they get older. In addition, females are more engaged in morality than males. However, it was determined that there is no relationship between the variables experience and branch and the variable moral disengagement in sports. In contrast to our findings, Gürpınar (2014) stated that athletes may differ in their tendency to demonstrate moral behaviors according to their branches. Likewise, it was found that Gold and Özsarı (2017) revealed that athletes engaged in athletics (Gold \& Özsarı, 2017) and volleyball players (Tsai \& Fung, 2005) demonstrate more moral and sporting behaviors than wrestlers and basketball players, respectively.

A significant and negative relationship was found between mental toughness and moral disengagement in sports at $1 \%$ significance, which means that a participant who is morally engaged in sports has a stronger mental toughness. Concordantly, higher scores in the SMTQ means that athletes may demonstrate more moral behaviors.

Regression equations (3) and (4) were established to determine the degree of interaction between the MDSS and SMTQ. Accordingly, it was found that the third model is statistically significant at $1 \%$ significance level, and that the variable moral disengagement in sports affects the variable mental toughness negatively and significantly at $1 \%$ significance level. In other words, the lower scores the participants get from the MDSS, the stronger mental toughness they have. It was also found that a decrease in moral values by 1 unit may cause an increase of 0.089 in mental toughness.

In Table 6, revealing the results of regression analysis conducted to determine the effect of mental toughness levels of the athletes on their moral disengagement in sports levels, it was found that the fourth model is statistically significant at $1 \%$ significance level. The variable mental toughness affects the variable moral disengagement in sports significantly and negatively at $1 \%$ significance level. In other words, it can be asserted that an increase in the scores in the SMTQ by 1 unit will cause a decrease of 0.396 in the MDSS, which means that such an increase will lead the athletes to be more engaged in moral values. Considering the results for the 3rd and 4th regression models, it was discovered that the effect of the variable mental toughness on the variable moral disengagement (0.396) is greater than vice versa (0.089). Consequently, it can be stated that improving the activities aiming at increasing the mental development of athletes will contribute to their mental toughness as well as to their moral engagement in sports.

Regression models numbered 5, 6 and 7 were established to determine the effects of three sub-scales of the SMTQ on the variable moral disengagement in sports. Accordingly, it was determined that the fifth model is statistically significant at $1 \%$ significance level, and that the constancy sub-scale has a negative effect on the MDSS at $1 \%$ significance level. An increase in the scores in the constancy sub-scale by 1 unit will cause a decrease of 0.343 in the MDSS, which means the greater constancy the athletes demonstrate, the further moral values they are engaged in.

Results for the regression model numbered 6 revealed that the sixth regression model is statistically insignificant at $10 \%$, which means there was no statistically significant relationship between the confidence sub-scale and the MDSS. Therefore, it can be asserted that the athlete's belief that $\mathrm{s} /$ he will successfully complete the desired behavior does not have an effect on moral disengagement. However, the scholars indicate that self-confident athletes believe that they will succeed and have the physical and mental skills to reveal their potential to succeed. This means that self-confident athletes can be calm and relaxed even under stress and can focus on more positive thoughts during the competition (Y1ldirım, 2013).

In the final finding of the study, it was concluded that the seventh model is statistically significant at $1 \%$ significance level, and that the control sub-scale has a negative effect on the MDSS at $1 \%$ significance level. In other words, an increase in the scores in the control sub-scale by 1 unit will cause a decrease of 0.272 in the MDSS, which means the greater control the athletes gain, the further the moral values they are engaged in. An athlete may find himself/herself in positive or negative scenarios during both his/her life and the competition. 
Especially during the competition, it is the behavior expected from an athlete having a strong mental toughness to transform the threats posed by the opponent, spectators, venue and teammates etc. into positive opportunities by coping with stress and anxiety. Therefore, it can be stated that athletes' beliefs that they have the necessary cognitive, motivational and behavioral resources and the capacity to mobilize these resources when necessary to control the events in their lives (Sheard, 2009) have an effect on moral disengagement.

Given the results for the SMTQ and MDSS, it may be suggested that providing training opportunities to athletes to enable them to improve themselves in terms of the themes covered by both scales will have positive contributions on both variables. Moreover, it can be stated that further intensification of training based on the themes covered by the constancy and control sub-scales, which are the sub-scales of the SMTQ, will contribute significantly to their engagement in moral values as well as improve their mental capabilities.

In conclusion, in this study which was conducted with the sample composed of elite athletes, while constancy and control subscales are significant predictors of the variable moral disengagement, but it is not the case for confidence subscale.

\section{References}

Altın, M., \& Özsarı, A. (2017). The Moral Decision-Making Attitudes of the Athletes Attending to Sport Training Centers. International Journal of Cultural and Social Studies (UKSAD), 3(1), 133-145. Retrieved from http://dergipark.org.tr/intjcss/issue/30960/337225

Boardley, I. D., \& Kavussanu, M. (2008). The moral disengagement in sport scale-short. Journal of Sports Sciences, 26(14), 1507-1517. https://doi.org/10.1080/02640410802315054

Cohen, L., Manion, L., \& Morrison, K. (2000). Research Methods in Education (5th ed.). London: Routledge Falmer. https://doi.org/10.4324/9780203224342

Connaughton, D., Wadey, R., Hanton, S., \& Jones, G. (2008). The development and maintenance of mental toughness: Perceptions of elite performers. Journal of Sports Sciences, 26(1), 83-95. https://doi.org/10.1080/02640410701310958

Crust, L. (2007). Mental toughness in sport: A review. International Journal of Sport and Exercise Psychology, 5(3), 270-290. https://doi.org/10.1080/1612197X.2007.9671836

Crust, L. (2008). A review and conceptual reexamination of mental toughness: Implications for future researchers. Personality and Individual Differences, 45(7), 576-583. https://doi.org/10.1016/j.paid.2008.07.005

Crust, L., Earle, K., Perry, J., Earle, F., Clough, A., \& Clough, P. J. (2014). Mental toughness in higher education: Relationships with achievement and progression in first-year university sports students. Personality and Individual Differences, 69, 87-91. https://doi.org/10.1016/j.paid.2014.05.016

Darren \& Mallery. (2014). IBM SPSS Statistics 23 Step by Step, A Simple Guide and Reference (14th ed.). New York: Routledge.

Goldberg, A. S. (1998). Sports Slump Busting: 10 Steps to Mental Toughness and Peak Performance, Champaign. IL: Human Kinetics.

Gucciardi, D. F., Hanton, S., \& Mallett, C. J. (2012). Progressing measurement in mental toughness: A case example of the Mental Toughness Questionnaire 48. Sport, Exercise, and Performance Psychology, 1(3), 194-214. https://doi.org/10.1037/a0027190

Gürpınar, B. (2014). Moral decision-making attitudes of athletes studying at middle and high school in terms of gender, educational background and sports. Education and Science Journal, 39(176), 413-424. https://doi.org/10.15390/EB.2014.3645

Gürpınar, B. (2015). Adaptation of The Moral Disengagement in Sport Scale-Short into Turkish Culture: A Validity and Reliability Study in A Turkish Sample, Ankara University School of Sports Sciences, 13(1), 57 64. http://dergiler.ankara.edu.tr/dergiler/17/2011/20970.pdf

Hunter, A. J. (2001). A cross-cultural comparison of resilience in adolescents. Journal of Pediatric Nursing, 16(3), 172-179 https://doi.org/10.1053/jpdn.2001.24180

Jones, G., Hanton, S., \& Connaughton, D. (2002). What is this thing called mental toughness? An investigation of elite sport performers. Journal of Applied Sport Psychology, 14, 205-218. https://doi.org/10.1080/10413200290103509

Karasar, N. (2006). Scientific research method. Ankara: Nobel Press. 
Kavussanu, M. (2008). Moral behaviour in sport: A critical review of the literature. International Review of Sport and Exercise Psychology, 1(2), 124-138. https://doi.org/10.1080/17509840802277417

Kline, P. (2014). An Essay Guide to Factor Analysis. New York: Routledge. https://doi.org/10.4324/9781315788135

Marchant, D. C., Polman, R. C., Clough, P. J., Jackson, J. G., Levy, A. R., \& Nicholls, A. R. (2009). Mental toughness: Managerial and age differences. Journal of Managerial Psychology, 24(5), 428-437. https://doi.org/10.1108/02683940910959753

Nicholls, A. R., Polman, R., Levy, A., \& Backhouse, S. H. (2009). Mental toughness in sport: Achievement level, gender, age, experience and sport type differences. Personality and Individual Differences, 47, 73-75. https://doi.org/10.1016/j.paid.2009.02.006

Pehlivan, H. (2014). Adaptation of Sports Mental Toughness Questionnaire (SMTQ): A Validity and Reliability Study. Master's Thesis, School of Health Sciences, Department of Physical Education and Sports, Celal Bayar University. Manisa.

Schermelleh-Engel, K., \& Moosbrugger, H. (2003). Evaluating the Fit of Structural Equation Models: Tests of Significance and Descriptive Goodness of Fit Measurement. Methods of Psychological Research Online, 8(2), 23-74. http://citeseerx.ist.psu.edu/viewdoc/download?doi=10.1.1.509.4258\&rep=rep1\&type=pdf

Sheard, M., Golby, J., \& Wersch, A. (2009). Progress Toward Construct Validation of the Sports Mental Toughness Questionnaire (SMTQ). European Journal of Psychological Assessment, 25(3), 186-193. https://doi.org/10.1027/1015-5759.25.3.186.

Sümer, N. (2000). Structural Equation Models. Turkish Psychology Publications, 3(6), 49-74.

Tabachnick, B. G., \& Fidell, L. S. (2007). Using multivariate statistics (5th ed.). New York: Allyn and Bacon.

Taylor, J. (1989). Mental toughness (Part 2): A simple reminder may be all you need. Sport Talk, 18, 2-3.

Tekkurşun, D. G., Namlı, S., Hazar, Z., Türkeli, A., \& Cicioğlu, İ. (2018). Investigation of Individual and Team Athletes' Decision-Making Styles and The Level of Mental Well-Being. CBU Journal of Physical Education and Sports Sciences, 13(1), 176-191. Retrieved from http://dergipark.org.tr/cbubesbd/issue/38083/417188

Tekkurşun, D. G., \& Türkeli, A. (2019). Examining the Exercise Addiction and Mental Toughness Levels of Students at Faculty of Sports Sciences. Journal of Sport Sciences Research, 4(1), 10-24. https://doi.org/10.25307/jssr.505941

Tsai, E., \& Fung, L. (2005). Sportspersonship in youth basketball and volleyball players. Athletic Insight, 7(2), 3746.

Wood, R., Hoctor, M., \& Desmond, R. (1995). Coaching tennis successfully. Champaign. IL: Human Kinetic.

Yarayan, Y. E., Yıldız, A. B., \& Gülşen, D. B. A. (2018). Examination of Mental Toughness Levels of Individual and Team Sports Players at Elite-Level According to Various Variables. International Journal of Social Research, 11(57), 992-999. https://doi.org/10.17719/jisr.2018.2509

\section{Copyrights}

Copyright for this article is retained by the author, with first publication rights granted to the journal.

This is an open-access article distributed under the terms and conditions of the Creative Commons Attribution license (http://creativecommons.org/licenses/by/4.0/). 